\title{
DIAGNÓSTICO ARQUIVÍSTICO: UMA PROPOSIÇÃO METODOLÓGICA A PARTIR DE INSTRUMENTOS NORMATIVOS DE DESCRIÇÃO ARQUIVÍSTICA
}

\author{
ARCHIVAL DIAGNOSIS: A METHODOLOGICAL \\ PROPOSITION FROM NORMATIVE INSTRUMENTS OF \\ ARCHIVAL DESCRIPTION
}

Leolíbia Luana Lindena

Marisa Bräscherb

\begin{abstract}
RESUMO
Introdução: Discorre sobre a importância e a necessidade de realização do diagnóstico arquivístico no que antecede qualquer intervenção arquivística no processo de gestão de documentos. Objetivo: Aborda conceitos e metodologias que a literatura da área tem utilizado na realização de diagnóstico arquivístico, a estrutura e os objetivos dos instrumentos normativos de descrição arquivística ISAD (G), ISAAR (CPF), ISDIAH e ISDF. Metodologia: Pesquisa bibliográfica e documental que alinha as informações propostas pela literatura para desenvolvimento de diagnóstico arquivístico com a estrutura de elementos descritivos dos instrumentos normativos de descrição arquivística, buscando identificar os conceitos e metodologias utilizadas no desenvolvimento de diagnóstico arquivístico. Resultados: Considera os elementos descritivos que compõe os instrumentos normativos de descrição arquivística suficientes para elencar informações necessárias ao desenvolvimento do diagnóstico arquivístico. Propõe a metodologia descritiva para o desenvolvimento de diagnóstico arquivístico utilizando os instrumentos normativos de descrição arquivística: ISAD (G), ISAAR (CPF), ISDIAH e ISDF. Conclusões: Indica a importância de determinar os elementos informativos a partir de instrumentos já padronizados que possam gerar diagnósticos arquivísticos capazes de corresponder às soluções arquivísticas de acordo com as reais necessidades institucionais.
\end{abstract}

Descritores: Diagnóstico arquivístico. Descrição arquivística. Instrumentos normativos de descrição arquivística. Normas de descrição arquivística.

a Doutoranda do Programa de Pós-graduação em Ciência da Informação da Universidade Federal de Santa Catarina (UFSC). E-mail: leolibialuana@gmail.com

b Doutora em Ciência da Informação pela Universidade de Brasília (UnB). Professora do Programa de Pós-graduação em Ciência da Informação da Universidade Federal de Santa Catarina (UFSC). E-mail: marisa.brascher@gmail.com 


\section{INTRODUÇÃO}

O volume de informação produzida na sociedade contemporânea traz como consequência o crescimento documentos arquivísticos, a necessidade de racionalização e gestão desses espaços. Nesse movimento, se aproxima da arquivologia os preceitos da administração, que trouxe a concepção de gestão de documentos na intenção de facilitar o fluxo de informação e a economia de recursos para a instituição.

Para que sejam pensadas estratégias de gestão de documentos que possam corresponder a demanda institucional, é importante conhecer a estrutura organizacional e arquivística do ambiente onde os arquivos são produzidos e/ou acondicionados. Para termos um maior conhecimento acerca dessa estrutura, é importante que se realize o diagnóstico arquivístico, procedimento que dá uma visão geral das informações institucionais e arquivísticas que caracterizam esse ambiente organizacional.

Esse estudo, se justifica pelo seu próprio objetivo em identificar os conceitos e metodologias utilizadas no desenvolvimento de diagnóstico arquivístico, a fim de propor uma metodologia para tal. Para isso procura-se identificar quais são os conceitos e metodologias que a literatura da área tem utilizado na realização de diagnóstico arquivístico; caracterizar a estrutura e os objetivos dos instrumentos normativos de descrição arquivística ISAD (G), ISAAR (CPF), ISDIAH e ISDF; e por fim alinhar as informações propostas pela literatura para desenvolvimento de diagnóstico arquivístico com a estrutura de elementos descritivos dos instrumentos normativos de descrição arquivística.

Ao final desse estudo procura-se responder a seguinte questão de pesquisa: de que forma os elementos descritivos que compõe os instrumentos normativos de descrição arquivística (ISAD (G), ISAAR (CPF), ISDIAH e ISDF) podem auxiliar na delimitação de informações necessárias para o desenvolvimento de um diagnóstico arquivístico? 


\section{GESTÃO DE DOCUMENTOS E DIAGNÓSTICO ARQUIVÍSTICO}

O desfecho da Segunda Guerra Mundial abriu caminhos para o capitalismo, instaurando-se a burocracia como um modelo de controle e por consequência a produção e o fluxo intenso de informações. Nesse contexto, a gestão de documentos emerge como uma alternativa para racionalizar a produção de documentos, assim como facilitar a busca destes documentos e regular sua eliminação ou guarda permanente.

$\mathrm{Na}$ primeira metade do Século $\mathrm{XX}$, os princípios de racionalidade administrativa se estabelecem após serem fomentados pelas intervenções realizadas nas etapas do ciclo vital dos documentos. Com a expansão e resultados efetivos das atividades de gestão documental, a ideia de documentos custodiados passa a ter noção de que os documentos podem ser eliminados dependendo dos valores a eles atribuídos (FONSECA, 1998, p. 34-38).

Nesse sentido, entende-se como conceito de gestão de documentos

[...] o conjunto de procedimentos e operações técnicas referentes à sua produção, tramitação, uso, avaliação e arquivamento em fase corrente e intermediária, visando a sua eliminação ou recolhimento para guarda permanente. (BRASIL, 1991, p. 1).

Em complemento, a Lei ainda enfatiza que é dever da instituição ou pessoa produtora dos documentos promover a gestão dos mesmos, assim como sua custódia.

Segundo o Dicionário Brasileiro de Terminologia Arquivística (ARQUIVO NACIONAL, 2005, p. 100), a gestão documental é "[...] o conjunto de medidas e rotinas visando à racionalização e eficiência na criação, tramitação, classificação e avaliação dos documentos."

De acordo com Indolfo (2007, p. 42) a gestão de documentos é útil para o controle do ciclo vital dos documentos, sua função torna-se primordial para garantir cada vez mais eficiência, eficácia e qualidade nos negócios, nas decisões e na preservação da memória.

Para Medeiros e Amaral (2010)

A gestão de documentos é um processo arquivístico que, com menor custo e maior eficiência e eficácia, busca intervir no ciclo de vida dos documentos, visando reduzir, seletiva e 
racionalmente, a massa documental a proporções manipuláveis até que a ela tenha destinação final (expurgo ou recolhimento aos arquivos permanentes). (MEDEIROS; AMARAL, 2010, p. 298)

Sendo assim, as atividades de gestão de documentos são imprescindíveis para o funcionamento organizado, racional, eficiente e dinâmico de uma instituição. É preciso compreender que o processo de gestão de documentos se dá quando no planejamento de política, plano ou programa de gestão que possibilite que os documentos estejam contemplados e tramitem de acordo com o proposto pelos instrumentos de gestão criados e gerenciados pela instituição.

Porém, as atividades de gestão de documentos precisam ser planejadas de acordo com a necessidade de cada instituição que a implanta, respeitando suas especificidades e seus fluxos informacionais. Para isso, se faz o uso do diagnóstico arquivístico, uma ferramenta gerencial que busca realizar 0 levantamento de informações arquivísticas para definir e conhecer as características de determinado acervo e instituição como uma atividade que integra o planejamento de uma política de gestão de documentos.

Nesse sentido, Calderon et al (2004) nos direciona:

[...] ao se propor um trabalho de gestão de documentos e informacional, é necessário, antes de qualquer iniciativa, conhecer bem a instituição/organização. Sem o conhecimento histórico sociológico das mesmas, torna-se difícil entender o ciclo da informação/documento. (CALDERON et al, 2004, p. 100)

Ferreira e Melo (2008 p. 02), enfatizam a importância da elaboração de diagnósticos como o primeiro passo na implantação de uma política de gestão de documentos, para que se possa pensar soluções para a gestão que correspondam às necessidades específicas das instituições.

Cornelsen e Nelli (2006) realizaram um estudo comparativo analisando as recomendações e sugestões dos trabalhos de Evans e Ketelaar (1983), Lopes (1997), Moneda Corrochano (1995), Campos et al (1986) e Rousseau e Couture (1998), traçando o perfil de cada uma das proposições metodológicas apresentando as diferentes denominações, objetivos, fases, assim como métodos e/ou técnicas que são utilizadas e sugeridas pelos referidos autores.

Lopes (2009) nos recorda que é necessário discutir e elaborar metodologias de diagnóstico arquivístico capazes de: 
Dar conta da investigação acurada dos problemas gerados pela presença das informações registradas de natureza arquivística atribuída e eleita como objeto de pesquisa e de tratamento; Delimitar questões referentes aos sujeitos, no que tange à formação teórica e profissional, ao modo de realizar pesquisas, propor as hipóteses, definir os objetivos, etc. (LOPES, 2009, p. 146).

O autor ainda indica que as informações podem ser coletadas de diversas maneiras, a partir de questionários, formulários, entrevistas e observação, até mesmo mais de uma metodologia pode ser usada. Dessa forma, amplia-se a possibilidade de conhecer a estrutura organizacional na qual se pretende realizar uma intervenção arquivística.

Para Cornelsen e Nelli (2006, p. 82) as principais informações a serem consideradas no processo de coleta de dados para o diagnóstico arquivístico seriam referentes à estrutura, às funções, às atividades e o fluxo de informações que permeiam a organização.

Cunha e Cavalcanti (2008, p. 122) defendem que as informações sobre quantidade, forma, tipo, localização, condições de conservação, taxa de acumulação, cronologia, frequência de utilização dos documentos seriam fundamentais para pensar a estrutura do diagnóstico arquivístico.

É por meio do diagnóstico arquivístico, que o arquivista terá as informações qualitativas e quantitativas sobre a organização do acervo, e a partir dessas informações poderá traçar estratégias e soluções baseadas em seu conhecimento teórico e prático sobre o fazer arquivístico, que o permitirão o planejamento e execução de políticas de gestão de documentos, estruturadas nas atividades de classificação, avaliação, recolhimento, conservação, armazenamento e demais atividades técnicas de responsabilidade do arquivista. (SILVA; MARINHO; SANTOS, 2007)

Coincidentemente, as atividades listadas nos estudos de Silva, Marinho e Santos (2007) são atividades consagradas como funções arquivísticas (classificação, avaliação, recolhimento, conservação, armazenamento), de acordo com a teoria defendida pela arquivística integrada. 


\section{FUNÇÕES ARQUIVÍSTICAS E DESCRIÇÃO ARQUIVÍSTICA}

Rousseau e Couture (1998), além de inaugurar a corrente integrada do pensamento arquivístico, preconizam as funções arquivísticas, que seriam as atividades norteadoras no contexto do arquivo. As funções fazem parte da gestão de documentos e ocorrem durante todo o ciclo de vida dos documentos de arquivo.

Aparentemente, as funções podem ser percebidas de maneira linear, ou que ocorram na sequência proposta pela Figura 6 . Mas as funções podem ser cumpridas de maneira dinâmica, gradual e até mesmo simultânea. Entre as funções, há as consideradas matriciais, que são: classificação, avaliação e descrição, que são o cerne técnico do fazer arquivístico.

Figura 1 - Ilustração das funções arquivísticas.

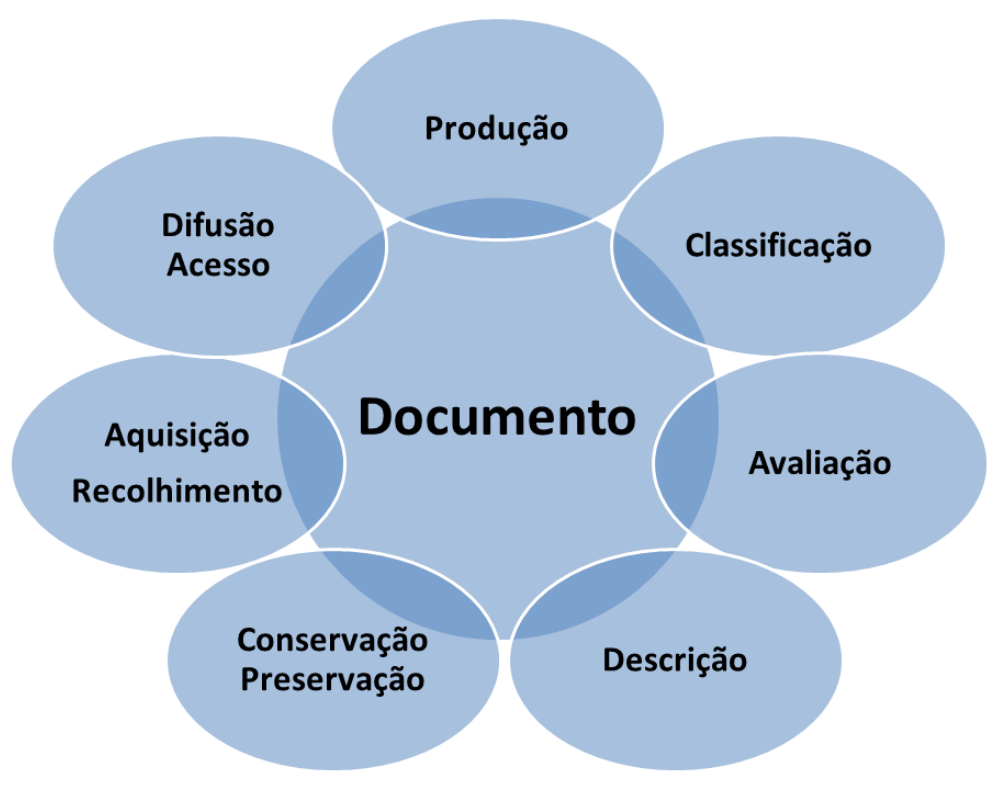

Fonte: Adaptado de Rousseau e Couture (1998).

Para melhor nos familiarizarmos com os conceitos desse estudo, iremos nos debruçar a partir de então, na função da descrição arquivística, compreendendo seu desenvolvimento e desdobramentos até a criação dos instrumentos normativos de descrição arquivística e suas características e funcionalidades.

Os primeiros registros conhecidos de descrição arquivística foram 
encontrados em Nuzi, na Assíria, em 1500 a.C., registrados em argila com formato de um repertório de documentos. Esses registros eram utilizados para fins administrativos, evitando a consulta direta aos documentos e facilitando o deslocamento repentino em caso de guerras ou sinistros, não para orientar em pesquisas ou controlar diferentes grupos de arquivos (DURANTI, 1993, p. 48).

Para Linares e Mena (2014) as civilizações antigas, como a mesopotâmica, a egípcia, a grega e a romana faziam uso do arquivo como um meio de controlar as atividades da vida econômica, política, religiosa e administrativa da sociedade, por meio de repertórios de documentos.

Durante a Idade Média houve uma concepção preocupada em garantir que os arquivos tivessem a responsabilidade de perpetuar as memórias, entendendo que os documentos preservados em arquivo seriam a prova autêntica e permanente de ações passadas (DURANTI, 1993, p. 49). Para Llanes Padrón (2016) ocorreu um retrocesso na descrição arquivística em relação à antiguidade: o surgimento de escribas nos monastérios reduziu a atividade de descrição ao trabalho destes. Assim, a descrição arquivística era desconhecida por ser associada à ação de copiar os documentos.

No século XIII, foi desenvolvido um método de descrição que tinha objetivos jurídico e administrativo: respectivamente para fornecer provas da existência dos documentos e manter o controle, de maneira a facilitar a obtenção dos documentos para negociações. Entre os séculos XVIII e XX na modernidade, os arquivos se voltaram ao serviço de pesquisa histórica, abrindo a porta de seus acervos para que os cidadãos pudessem ter acesso. Essa ação, tem reflexos das características dos ideais da Revolução Francesa de liberdade, igualdade e fraternidade que influenciaram movimentos no mundo todo.

Para Llanes Padrón (2016), este foi o momento que a descrição e a classificação arquivística se convertem em processos integrados e os arquivistas criaram métodos de organização e estabeleceram a ordem que os documentos deveriam estar representados nos instrumentos de pesquisa, em um modelo pensado para estudos históricos. O método de classificação a ser utilizado na maior parte das instituições nesse período foi o temático. Com isso, fundos foram desmembrados e os documentos perderam a origem de sua formação. 
$\mathrm{Na}$ Idade Contemporânea, quando a arquivística passa a incorporar seu corpo científico, temos a delimitação quanto aos seus princípios teóricos: Princípio do Respeito aos Fundos e Princípio da Ordem Original. Com isso, a descrição passa a ser um processo de tratamento arquivístico independente da classificação e passa a descrever não só o documento e seu conteúdo, mas também informações sobre suas características, de seus produtores e de seus contextos de criação.

Em resumo, pode-se perceber que na antiguidade a descrição servia para responder aos interesses da administração e evidenciar a existência dos documentos; no período medieval, a descrição foi confundida com a atividade de transcrever documentos; na modernidade a descrição se destinou a conservar o significado das ações registradas nos documentos; na idade contemporânea a descrição se adapta aos princípios arquivísticos ao integrar-se com demais funções arquivísticas, como a classificação, facilitando a recuperação e o acesso aos documentos.

Para o Dicionário Brasileiro de Terminologia Arquivística (ARQUIVO NACIONAL, 2005, p. 67), Descrição Arquivística é o "conjunto de procedimentos que leva em conta os elementos formais e de conteúdo dos documentos para elaboração de instrumentos de pesquisa." Portanto, esta pode ser considerada a criação de representações para a informação arquivística, que tem como objetivo principal:

[...] identificar e explicar o contexto e o conteúdo de documentos de arquivo a fim de promover o acesso aos mesmos. Isto é alcançado pela criação de representações precisas e adequadas e pela organização dessas representações de acordo com modelos predeterminados. Processos relacionados à descrição podem começar na, ou antes, da produção dos documentos e continuam durante sua vida (CONARQ, 2000, p.11)

Heredia Herrera (1991, p. 300) define que "a descrição é a ponte que liga o documento com os usuários", com essa analogia a autora traz a perspectiva de que por meio da descrição arquivística é possível conhecer o conteúdo de um arquivo e, assim, se torna possível ao usuário desenvolver suas pesquisas.

Llanes Padrón (2016), indica as características da descrição arquivística nos diferentes paradigmas arquivísticos, como indica o Quadro 1. 


\section{Quadro 1 - Funções da Descrição Arquivística em cada Paradigma Arquivístico}

\begin{tabular}{|c|c|c|}
\hline PARADIGMAS & FUNÇÃO & OBJETOS \\
\hline $\begin{array}{c}\text { Pré-Arquivístico } \\
(4000 \text { a. n. e - Sec.XIX) }\end{array}$ & Conservar significado e provas & Repertório de documentos \\
\hline $\begin{array}{c}\text { Custodial } \\
(1898-1980)\end{array}$ & $\begin{array}{c}\text { Manter controle e proporcionar } \\
\text { acesso }\end{array}$ & Instrumentos de pesquisa \\
\hline $\begin{array}{c}\text { Pós-Custodial } \\
(1980-\text { atualidade })\end{array}$ & Manter autenticidade e evidência & $\begin{array}{c}\text { Padronização da descrição; } \\
\text { Énfase na atividade de descrever }\end{array}$ \\
\hline
\end{tabular}

Fonte: Llanes Padrón (2016).

A partir das delimitações da autora é possível perceber o desenvolvimento da descrição ao perpassar entre os diferentes paradigmas da arquivística. Partindo de uma perspectiva empírica, onde a criação de instrumentos de pesquisa como produtos da descrição era o foco e, posteriormente a padronização da descrição com o uso de normas e manuais, até chegar em um prisma reflexivo sobre o processo de descrever focado na representação como ocorre na atualidade.

Em 1989 foi criada uma comissão com representantes de vários países por meio do Conselho Internacional de Arquivos (CIA), designada a realizar a tarefa de estabelecer padrões para a descrição arquivística. Em 1994, obtém-se o resultado dos estudos realizados por essa comissão com a publicação da $\operatorname{ISAD}(G)$ que se aplica a documentos de qualquer suporte. Em 1996, foi lançada a ISAAR(CPF) que regula a descrição da entidade produtora, dessa forma as duas normas se complementam.

Posteriormente, para auxiliar na descrição do contexto do produtor dos documentos o CIA lançou duas outras normas: ISDIAH e ISDF. A ISDIAH é a norma internacional que se encarrega de apontar os elementos para descrição de instituições com acervo arquivístico, enquanto a ISDF é a norma internacional para descrição de funções, que indica em seus aspectos descritivos as especificidades das funções e atividades da entidade produtora.

O objetivo da padronização do processo de descrição arquivística estaria diretamente relacionado com a garantia da eficiência e efetividade no processo de pesquisa, otimização do trabalho do arquivista e a familiarização com o acervo que está sendo descrito (FOX, 2007, p. 28) 
Nessa direção, cada uma das normas de descrição proposta pelo CIA teria um objeto diferente a ser descrito, como expresso, respectivamente no Quadro 2.

\section{Quadro 2 - Instrumentos normativos de descrição arquivística e seus respectivos objetos de descrição.}

\begin{tabular}{|l|l|}
\hline NORMAS DE DESCRIÇÃO ARQUIVÍSTICA & OBJETO DE DESCRIÇÃO \\
\hline $\begin{array}{l}\text { ISAD (G): Norma Internacional de Descrição } \\
\text { Arquivística }\end{array}$ & Documentos \\
\hline $\begin{array}{l}\text { ISAAR (CPF): Norma Internacional de Registro de } \\
\text { Autoridade Arquivística para Entidades Coletivas, } \\
\text { Pessoas e Famílias }\end{array}$ & Autoridades \\
\hline $\begin{array}{l}\text { ISDIAH: Norma Internacional para Descrição de } \\
\text { Instituições com Acervo Arquivístico. }\end{array}$ & Instituições \\
\hline $\begin{array}{l}\text { ISDF: Norma Internacional para Descrição de } \\
\text { Funções }\end{array}$ & Funções \\
\hline
\end{tabular}

Fonte: CONARQ $(2000 ; 2004 ; 2008 ; 2009)$.

Cada uma das normas possui uma estrutura diferente, mesmo que convergindo em alguns elementos, que permite melhor representar os objetos que são foco da respectiva descrição.

\section{METODOLOGIA}

A metodologia utilizada no desenvolvimento desse estudo foi dividido em duas etapas: a primeira delas acerca da revisão de literatura sobre conceitos e metodologias aplicadas ao diagnóstico arquivístico; a segunda parte foi a pesquisa documental de instrumentos normativos de descrição arquivística internacionais propostas pelo Conselho Internacional de Arquivos.

Na primeira etapa foi realizada a revisão de literatura em bases de dados que mais abrangem a produção científica da área de Ciência da Informação no Brasil, são elas: a Base de Dados Referenciais de Artigos de Periódicos em Ciência da Informação (BRAPCI); a base da Biblioteca Digital Brasileira de Teses e Dissertações (BDTD); a base BENANCIB que contempla os anais do Encontro Nacional de Pesquisa e Pós-Graduação em Ciência da Informação (ENANCIB) desde 1994. Os termos utilizados para as buscas em todas as bases foram: 
diagnóstico arquivístico; diagnóstico de/em arquivo (sem aspas no buscador). A busca pelos termos definidos foi realizada em título, palavras-chave e resumos disponíveis nas referidas bases.

A partir dos documentos recuperados realizou-se a leitura sumária do conteúdo do documento na busca de possíveis tentativas de conceituação e metodologia de diagnóstico arquivístico, conforme prevê os objetivos específicos deste estudo. Os documentos que indicam o conceito ou metodologia foram categorizados como documentos recuperados relevantes. Os resultados dos documentos recuperados e documentos recuperados relevantes estão apresentados, respectivamente, no Quadro 3.

\section{Quadro 3 - Quantidade de documentos recuperados em cada base utilizando o buscador "diagnóstico arquivístico" e "diagnóstico de/em arquivo".}

\begin{tabular}{|l|l|l|}
\hline BASE DE DADOS & $\begin{array}{l}\text { DOCUMENTOS } \\
\text { RECUPERADOS }\end{array}$ & $\begin{array}{l}\text { DOCUMENTOS RECUPERADOS } \\
\text { RELEVANTES }\end{array}$ \\
\hline BRAPCI & 5 & 4 \\
\hline BENANCIB & 3 & 1 \\
\hline BDTD & 10 & 3 \\
\hline
\end{tabular}

Fonte: Dados da pesquisa (2018).

Na segunda etapa, foi realizada pesquisa documental no website do Conselho Internacional de Arquivos para identificação e caracterização da estrutura e formato dos instrumentos normativos de descrição arquivística internacionais, que resultou na identificação das seguintes normas internacionais de descrição arquivística: Norma Internacional de Descrição Arquivística (ISAD(G), 2000), Norma Internacional de Registro de Autoridade Arquivística para. Entidades Coletivas, Pessoas e Famílias (ISAAR, 2003), Norma Internacional para Descrição de Instituições com. Acervo Arquivístico (ISDIAH, 2008b) e Norma Internacional para a Descrição de Funções (ISDF, 2008a).

\section{ANÁLISE E DISCUSSÃO DOS RESULTADOS}

Nessa seção do texto serão analisados e discutidos os resultados desse 
estudo quanto aos conceitos e metodologias que a literatura aponta para realização de diagnósticos; identificação e caracterização dos instrumentos normativos de descrição arquivística; e proposições de reflexões acerca do uso desses instrumentos como metodologia de levantamento de informações para o desenvolvimento do diagnóstico arquivístico.

a) Conceitos e metodologias que a literatura da área tem utilizado na realização de diagnóstico arquivístico;

No Quadro 4 estão apresentadas as referências dos documentos recuperados que são relevantes para a proposta dessa análise e suas respectivas bases de onde foram recuperadas.

\section{Quadro 4 - Documentos relevantes recuperados nas respectivas bases de dados.}

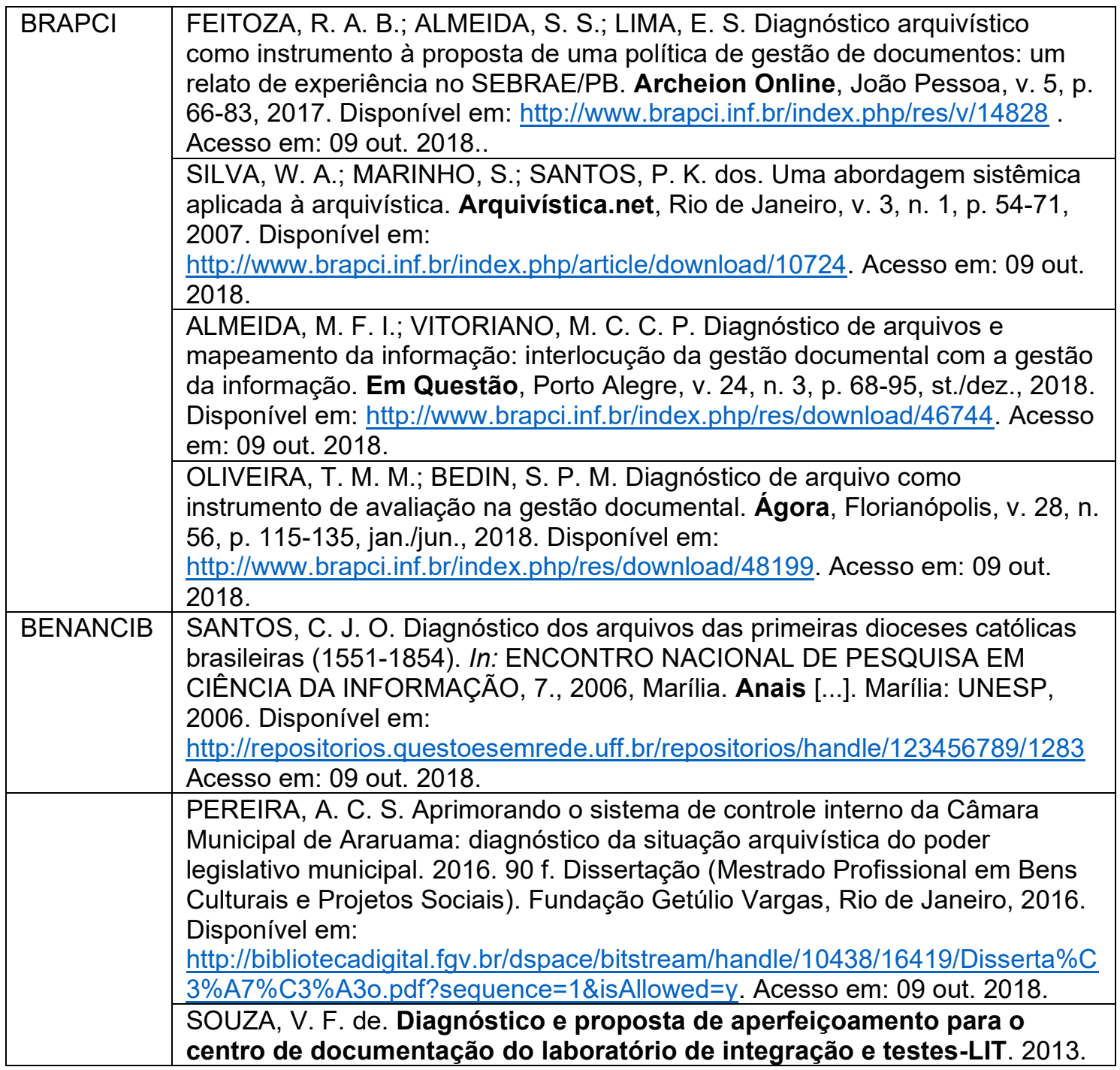




\begin{tabular}{|c|l|}
\hline BDTD & $\begin{array}{l}\text { 140 f. Dissertação (Mestrado em Gestão e Desenvolvimento Regional). } \\
\text { Universidade de Taubaté, Taubaté, SP, 2013. Disponível em: } \\
\text { http://www.bdtd.unitau.br/tedesimplificado/tde_busca/arquivo.php?codArquivo= } \\
\text { 705. Acesso em: 09 out. 2018. }\end{array}$ \\
\cline { 2 - 3 } & $\begin{array}{l}\text { VARGAS, L. R. Seção de arquivo permanente do Arquivo Central da } \\
\text { Universidade Federal do Rio Grande do Sul: diagnóstico sobre a } \\
\text { preservação, a descrição e a difusão dos fundos UPA e URGS. 2017. } 213 \mathrm{f} . \\
\text { Dissertação (Mestrado em Memória Social e Bens Culturais). Universidade La } \\
\text { Salle. Rio de Janeiro. Disponível em: } \\
\text { https://lume.ufrgs.br/bitstream/handle/10183/171733/001056897.pdf? sequence }\end{array}$ \\
\hline \begin{tabular}{l} 
E1\&isAllowed=y. Acesso em: 09 out. 2018. \\
\hline
\end{tabular}
\end{tabular}

Fonte: Dados da pesquisa (2018).

Feitoza, Almeida e Lima (2017) relataram em seu trabalho a experiência vivenciada no arquivo do Sebrae/PB sobre a importância do diagnóstico arquivístico como instrumento à proposta de gestão de documentos a partir de uma política para o atendimento das necessidades de informação específicas. Por meio do diagnóstico arquivístico foi possível traçar um mapeamento das atividades da instituição referentes à documentação produzida, fluxo documental e a situação dos arquivos nas diferentes unidades. Dessa forma, as autoras compreendem o diagnóstico como uma "ferramenta que permite conhecer o status quo e a partir das informações, promover intervenções voltadas para a melhoria dos serviços [...].

O relatório do diagnóstico arquivístico foi construído com base na observação participativa, por meio de visitas nos ambientes de arquivo, além da aplicação de questionário, entrevistas, registros das observações feitas pelos entrevistados e registros fotográficos dos locais de guarda de documentos. A estrutura do documento apresentava a seguintes informações: identificação da organização; funções e atividades dos colaboradores envolvidos diretamente na produção dos documentos; recursos tecnológicos; recursos materiais; práticas atuais da gestão de documentos e suas lacunas; condições do ambiente dos arquivos (espaço físico, climatização, iluminação, etc), mobiliário, e o acondicionamento da documentação, e indicação de volume documental acumulado.

Silva, Marinho e Santos (2007) propõe um estudo acerca da aplicação do raciocínio sistêmico e suas leis (Visão Sistêmica, Princípio de Alavancagem e Feedback de Compensação) nas atividades arquivística. Dessa forma, a partir 
da perspectiva do raciocínio sistêmico, os autores compreendem que é com o diagnóstico arquivístico, que o arquivista obterá informações quantitativas e qualitativas sobre a organização e seu acervo, que os possibilitarão o planejamento e a execução de programas de conservação, classificação, avaliação, recolhimento, transferência, armazenamento, acondicionamento, microfilmagem e demais atividades arquivística.

Na visão desses autores, ao desenvolver o diagnóstico arquivístico esse profissional precisa fazer uso de seus conhecimentos metodológicos e científicos, da sua criatividade, da sua capacidade de visão crítica, tornando-se num eficiente e eficaz observador, situando essas competências como fundamentais no ato de diagnosticar.

Almeida e Vitoriano (2018) trazem à discussão as possíveis contribuições da metodologia Infomapping, comumente aplicada à área de gestão da informação no mapeamento de fluxos informacionais, para o diagnóstico arquivístico. As autoras relatam que é comum a ambiguidade terminológica entre diagnóstico arquivístico e o processo de identificação.

É feito um levantamento teórico acerca dos estudos que, no julgamento das autoras, dão um melhor embasamento ao desenvolvimento do diagnóstico arquivístico baseado em Moneda Corrochano (1995), Pazin (2005), Lopes (2009). A partir da caracterização de diagnóstico arquivístico fundamentados nas metodologias propostas pelos autores acima citados, o estudo alinhou as características de diagnóstico arquivístico com as etapas da metodologia Infomapping indicando os aspectos convergentes, enfatizando a importância de consolidar diferentes metodologias, ferramentas e instrumentos.

Oliveira e Bedin (2018) se propõe a investigar de que maneira o diagnóstico arquivístico pode contribuir no processo de avaliação de programas de gestão documental, partindo do pressuposto de que o diagnóstico levanta os elementos necessários que estão relacionados ao gerenciamento da informação e destaca soluções que priorizam mudança no tratamento dos documentos, direcionando as ações que precisam ser tomadas, não apenas como uma prática que determine as primeiras atividades a serem adotadas na intervenção documental, mas também durante a implantação e andamento da gestão de 
documentos objetivando sua avaliação.

Baseadas nas metodologias de diagnóstico arquivístico elencadas por Cornelsen e Nelli (2006), as autoras evidenciam as proposições metodológicas de Evans e Ketelaar (1983), Campos et al (1986), Moneda Corrochano (1995), Lopes (1997) e Rousseau e Couture (1998) alinhando as orientações em aspectos convergentes, entre eles a forma de levantamento das informações para compor o diagnóstico: questionário, entrevista, observação direta.

Santos (2006) procura descrever sobre as práticas arquivísticas dos arquivos das primeiras prelazias e dioceses brasileiras criada antes do fim do regime do padroado por meio de diagnóstico arquivístico. Como instrumento de coleta de dados, foi elaborado um modelo de questionário constituído de elementos da Norma internacional de Descrição Arquivística (ISAD(G)) e a partir das respostas obtidas foram elaboradas algumas planilhas de análise, destacando os aspectos que considerados mais importantes quanto à gestão e ao funcionamento de um arquivo, tendo como parâmetros de análise a legislação vigente para esse perfil institucional, sendo eles: tipologias de arquivos; projetos e coordenação das atividades; regulamento interno; personalidade jurídica; caráter associativo; orçamento; instalações físicas; medidas de preservação e acesso; catalogação; acessibilidade; instrumentos de pesquisa; recursos humanos; tecnologias da informação; e fundos documentais dispersos.

Pereira (2016) em sua pesquisa de mestrado procura propor um diagnóstico da situação arquivística da Câmara Municipal de Araruama, descrevendo e analisando de que forma se dá a organização, a gestão e a disponibilização de documentos por parte do poder legislativo daquele município. Como forma de coletar dados para compor o diagnóstico arquivístico foram utilizadas entrevistas com os servidores da instituição

Esse diagnóstico teria como objetivos: a) identificar padrões de organização e gestão de documentos presentes no órgão, b) identificar erros e propor medidas que busquem melhorias na gestão do arquivo, c) permitir conhecer como se encontra a instituição no que se refere à gestão da informação arquivística, disponibilizando informações sobre: volume documental, condições de armazenamento, espaço físico ocupado, recursos humanos dedicados à 
gestão do arquivo e percepções de servidores a respeito do tema.

Souza (2013) em sua dissertação objetiva identificar e analisar os problemas enfrentados pelo Centro de Documentação (CEDOC) do LIT/INPE e propor a realização de um diagnóstico para identificar as melhorias e as políticas necessárias à implantação de um Procedimento Técnico de Processos Arquivísticos e de um Manual de Gestão Documental para o aperfeiçoamento do CEDOC. Dessa forma, a autora utiliza do diagnóstico arquivístico como uma metodologia para proposição de novas práticas para a instituição, composto por questões relacionadas à instituição, documentação, atividades desenvolvidas, material, mobiliário e recursos humanos.

O autor não traz fundamentação teórica sobre diagnóstico arquivístico e não relata quais foram as bases para definir os elementos informacionais que compõe o instrumento de coleta de dados, que foi apresentado à instituição em formato de questionário.

Em sua dissertação, Vargas (2017) visa contribuir para a preservação, a descrição e a difusão dos Fundos documentais UPA e URGS, que estão sob custódia do Arquivo Central da UFRGS, procedendo a um diagnóstico desses fundos, visando sua caracterização como patrimônio cultural do tipo documental da UFRGS e proposição de um plano de ação para intervenção no acervo.

Para a autora, diagnóstico é um método de intervenção em que se faz o levantamento das atividades, do fluxo de informações, da estrutura e de aspectos relacionados aos acervos, tendo em vista a descrição da situação arquivística dos acervos de uma instituição/organização. Para as finalidades dessa pesquisa foi elaborado levando-se em consideração os aspectos do acervo e suas dimensões, da infraestrutura e as condições ambientais do local de armazenamento, das condições de preservação e conservação dos fundos.

De acordo com a análise realizada em cada um dos trabalhos recuperados, o conceito de diagnóstico arquivístico é percebido como uma ferramenta utilizada para identificar as características institucionais e arquivísticas de uma organização, traçando um mapeamento da realidade para que a partir dos fatos e atuais práticas seja possível pensar novas proposições e planejar as atividades de intervenção arquivística que estarão contempladas 
na política de gestão arquivística.

Entre as metodologias utilizadas para a coleta das informações institucionais e arquivísticas estão: questionários, entrevistas, observações, registros fotográficos e pesquisas no próprio acervo para melhor compreender a realidade arquivística. Observou-se também, o uso de metodologias de raciocínio sistêmico, Infomapping e alguns elementos descritivos da ISAD(G) na captura de informações para compor o diagnóstico arquivístico. Essa análise evidencia a ampliação das metodologias para realizar o diagnóstico arquivístico, quando se busca em outras áreas do conhecimento diferentes procedimentos metodológicos e em perceber que os elementos descritivos propostos da ISAD $(G)$ podem colaborar para um processo uniforme de coleta de informações.

Como elementos descritivos que compõe o diagnóstico arquivístico, existem muitas informações que os estudos apontaram em comum, que aqui podemos classificar em duas categorias diferentes, institucionais e arquivísticas. $\mathrm{Na}$ categoria institucional, se destacam as informações acerca da personalidade jurídica, regulamentos e normativas, estrutura organizacional da instituição; na categoria de informações arquivísticas, se destacam os aspectos focados no acervo quanto à sua organização (classificação e instrumentos de pesquisa), volume, conservação, preservação, acesso, recursos humanos e infraestrutura.

b) Estrutura e os objetivos dos instrumentos normativos de descrição arquivística: ISAD (G), ISAAR (CPF), ISDIAH e ISDF;

A $\operatorname{ISAD}(G)$ foi desenvolvida pela comissão ad hoc de Normas de Descrição que em 1989 foi criada com representantes de vários países por meio do Conselho Internacional de Arquivos (CIA), designada a realizar a tarefa de estabelecer padrões para a descrição arquivística. Em 1994, obtêm-se o resultado dos estudos realizados por essa comissão com a publicação da ISAD (G) que possibilita ser aplicada a documentos de qualquer suporte.

Corroborando com o desenvolvimento da área, de acordo com CONARQ (2000, p.12), as "Normas de descrição arquivística são baseadas em princípios teóricos aceitos. Por exemplo, o princípio de que a descrição arquivística procede do geral para o particular é uma conseqüência prática do princípio do respeito ao fundo." 
Essa perspectiva, também nos traz a técnica aplicados à própria descrição, quando se trata de documentos arquivísticos, que seria a descrição multinível, onde a descrição ocorre de acordo com os níveis estabelecidos pela classificação arquivística. Para que se dê em funcionamento, a descrição multinível possui quatro regras que são fundamentais: a) Descrição do geral para o particular: Representar o contexto e a estrutura hierárquica do fundo e suas partes componentes; b) Informação relevante para o nível de descrição: Representar com rigor o contexto e o conteúdo da unidade de descrição; c) Relação entre descrições: Tornar explícita a posição da unidade de descrição na hierarquia; e d) Não repetição de informação: Evitar redundância de informação em descrições hierarquicamente relacionadas. (CONARQ, 2000, p.18)

Sua estrutura identifica e define 26 elementos, agrupados em 7 áreas, que podem ser combinados e considerados para constituir a descrição de um acervo. No Quadro 5, temos a descrição de cada uma das áreas que compõe a ISAD $(G)$, suas respectivas funções e elementos de descrição.

Quadro 5 - Estrutura dos Elementos de descrição da ISAD (G)

\begin{tabular}{|c|c|c|}
\hline ÁREA & FUNÇÃO & ELEMENTOS DE DESCRIÇÃO \\
\hline 1) Identificação & 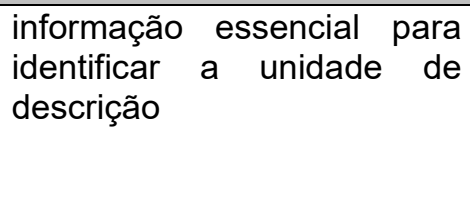 & $\begin{array}{l}1 \text { Código(s) de referência } \\
2 \text { Título } \\
3 \text { Data(s) } \\
4 \text { Nível de descrição } \\
5 \text { Dimensão e suporte }\end{array}$ \\
\hline Contextualização & $\begin{array}{l}\text { informação sobre a origem e } \\
\text { custódia da unidade de } \\
\text { descrição }\end{array}$ & $\begin{array}{l}6 \text { Nome(s) do(s) produtor(es) } \\
7 \text { História administrativa/Biografia } \\
8 \text { História arquivística } \\
9 \text { Procedência }\end{array}$ \\
\hline $\begin{array}{l}\text { 3) Conteúdo } \\
\text { estrutura }\end{array}$ & $\begin{array}{l}\text { informação sobre o assunto e } \\
\text { organização da unidade de } \\
\text { descrição }\end{array}$ & $\begin{array}{l}10 \text { Âmbito e conteúdo } \\
11 \text { Avaliação, eliminação e } \\
\text { temporalidade } \\
12 \text { Incorporações } \\
13 \text { Sistema de arranjo }\end{array}$ \\
\hline $\begin{array}{ll}\text { 4) Condições } & \text { de } \\
\text { acesso e uso } & \end{array}$ & $\begin{array}{l}\text { informação sobre a } \\
\text { acessibilidade da unidade de } \\
\text { descrição }\end{array}$ & $\begin{array}{l}14 \text { Condições de acesso } \\
15 \text { Condições de reprodução } \\
16 \text { Idioma } \\
17 \text { Características físicas e } \\
\text { requisitos técnicos } \\
18 \text { Instrumentos de pesquisa }\end{array}$ \\
\hline 5) Fontes relacionadas & $\begin{array}{l}\text { informação sobre fontes com } \\
\text { uma relação importante com } \\
\text { a unidade de descrição }\end{array}$ & $\begin{array}{l}19 \text { Existência e localização dos } \\
\text { originais } \\
20 \text { Existência e localização de } \\
\text { cópias } 21 \text { Unidades de descrição }\end{array}$ \\
\hline
\end{tabular}




\begin{tabular}{|l|l|l|}
\hline & & $\begin{array}{l}\text { relacionadas 22 Nota sobre } \\
\text { publicação }\end{array}$ \\
\hline 6$)$ Notas & $\begin{array}{l}\text { informação especializada ou } \\
\text { a qualquer outra informação } \\
\text { que não possa ser incluída } \\
\text { em nenhuma das outras } \\
\text { áreas da }\end{array}$ & $\begin{array}{l}\text { informação sobre como, } \\
\text { quando e por quem a } \\
\text { descrição arquivística foi } \\
\text { elaborada 25 Regras ou convenções }\end{array}$ \\
\hline 7) $\begin{array}{l}\text { Controle } \\
\text { descrição }\end{array}$ & \\
\hline
\end{tabular}

Fonte: Adaptado de CONARQ, 2000.

A primeira edição da ISAAR (CPF) foi desenvolvida pela Comissão $A d$ Hoc de Normas de Descrição do Conselho Internacional de Arquivos (CIA) entre 1993-1995 e publicada em 1996. Mais tarde, o Comitê de Normas de Descrição (CIA/CND) empreendeu a revisão da ISAAR (CPF) como sua primeira tarefa no programa de trabalho para o quadriênio 2000-2004, em uma ampla revisão, contando com propostas de instituições profissionais e pesquisadores do mundo todo. (CONARQ, 2004)

O principal objetivo da ISAAR (CPF) é determinar os tipos de informação que podem ser incluídos em um registro de autoridade e fornecer orientações sobre como esses registros podem ser desdobrados em um sistema de controle descritivo. Sua estrutura define 27 elementos de descrição, que são agrupados em 4 áreas, podendo ser utilizados no registro de autoridade proposto pela norma, conforme apresentado no Quadro 6.

\section{Quadro 6 - Estrutura dos Elementos de descrição da ISAAR (G)}

\begin{tabular}{|l|l|l|}
\hline ÁREA & FUNÇÃO & ELEMENTOS DE DESCRIÇÃO \\
\hline 1) Identificação & informação visa identificar & 1 Tipo de entidade \\
& especificamente a a & 2 Forma(s) autorizada(s) do nome \\
& entidade que está sendo & 3 Formas paralelas do nome \\
& descrita e são definidos & 4 Formas normalizadas do nome de \\
& pontos de acesso & acordo com outras regras \\
& normalizados para o o & 5 Outras formas do nome \\
& registro & 6 Identificadores para entidades \\
& & coletivas \\
\hline 2) Descrição & informação pertinente & 7 Datas de existência \\
& sobre a natureza, contexto & 8 História \\
& e atividades da entidade & 9 Locais \\
& que está sendo descrita & 10 Status legal \\
& 11 Funções, ocupações e atividades \\
& 12 Mandatos/Fontes de autoridade \\
\hline
\end{tabular}




\begin{tabular}{|c|c|c|}
\hline & & $\begin{array}{l}13 \text { Estruturas internas/Genealogia } \\
14 \text { Contexto geral }\end{array}$ \\
\hline 3) Relacionamentos & $\begin{array}{l}\text { relações com outras } \\
\text { entidades coletivas, } \\
\text { pessoas e/ou famílias são } \\
\text { registradas e descritas }\end{array}$ & $\begin{array}{l}15 \text { Nomes/ldentificadores das entidades } \\
\text { coletivas, pessoas ou famílias } \\
\text { relacionadas } \\
16 \text { Categoria do relacionamento } \\
17 \text { Descrição do relacionamento } \\
18 \text { Datas do relacionamento }\end{array}$ \\
\hline 4) Controle & $\begin{array}{l}\text { registro de autoridade é } \\
\text { especificamente } \\
\text { identificado e é registrada } \\
\text { a informação sobre como, } \\
\text { quando e por qual } \\
\text { instituição foi criado e } \\
\text { mantido }\end{array}$ & $\begin{array}{l}19 \text { Identificador do registro de } \\
\text { autoridade } 20 \text { Identificadores da } \\
\text { instituição } \\
21 \text { Regras e/ou convenções } \\
22 \text { Status } \\
23 \text { Nível de detalhamento } \\
24 \text { Datas de criação, revisão ou } \\
\text { obsolescência } \\
25 \text { Idioma(s) e sistema(s) de escrita } \\
26 \text { Fontes } \\
27 \text { Notas de manutenção }\end{array}$ \\
\hline
\end{tabular}

Fonte: Adaptado de CONARQ, 2004.

A ISAAR (CPF), em seu sexto capítulo, indica diretrizes para associar registros de autoridade arquivística a descrições de documentos produzidos pela entidade e/ou outros recursos de informação sobre ou por ela produzidos, incluindo modelos de dados que ilustram essas relações que descrevem produtores de documentos arquivísticos e descrições dos arquivos produzidos por essas entidades.

A ISDIAH foi criada pelo Comitê de Boas Práticas e Normas (CIA/CBPN), onde um grupo de trabalho foi criado para esboçar uma norma acerca das instituições que custodiam materiais arquivísticos e dos serviços que oferecem aos usuários, conforme sugerido por alguns membros da comunidade arquivística internacional, tendo sua versão final apresentada e publicada em 2008 (CONARQ, 2009)

A referida norma, determina alguns elementos informacionais que poderiam ser incluídos em descrições de instituições que possuem acervo arquivístico e fornece orientação sobre como essas descrições podem ser desenvolvidas em um sistema de descrição arquivística. Sua estrutura define 31 elementos de descrição, agrupados em 6 áreas conforme apresentado no Quadro 7. 
Quadro 7 - Estrutura dos Elementos de descrição da ISDIAH.

\begin{tabular}{|c|c|c|}
\hline ÁREA & FUNÇÃO & ELEMENTOS DE DESCRIÇÃO \\
\hline 1) Identificação & $\begin{array}{l}\text { informação visa identificar, } \\
\text { especificamente, a instituição } \\
\text { com acervo arquivístico e } \\
\text { definir pontos de acesso } \\
\text { normalizados }\end{array}$ & $\begin{array}{l}1 \text { Identificador } \\
2 \text { Forma(s) autorizada(s) do nome } \\
3 \text { Forma(s) paralela(s) do nome } \\
4 \text { Outra(s) forma(s) do nome } \\
5 \text { Tipo da instituição com acervo } \\
\text { arquivística }\end{array}$ \\
\hline 2) Contato & $\begin{array}{lcr}\text { informação } & \text { sobre } & \text { como } \\
\text { contatar a instituição } & \text { com } \\
\text { acervo arquivístico } & \end{array}$ & $\begin{array}{l}6 \text { Endereço(s) } \\
7 \text { Telefone, fax, correio eletrônico } \\
8 \text { Responsáveis para contato }\end{array}$ \\
\hline 3) Descrição & $\begin{array}{l}\text { informação relevante acerca da } \\
\text { história, estrutura atual e } \\
\text { política de entrada de } \\
\text { documentos da instituição com } \\
\text { acervo arquivístico }\end{array}$ & $\begin{array}{l}9 \text { História da instituição com acervo } \\
\text { arquivístico } \\
10 \text { Contexto geográfico e cultural } \\
11 \text { Mandatos/Fontes de autoridade } \\
12 \text { Estrutura administrativa } \\
13 \text { Políticas de gestão e de entrada de } \\
\text { documentos } \\
14 \text { Prédio(s) } \\
15 \text { Acervo arquivístico e outros } \\
\text { acervos } \\
16 \text { Instrumentos de pesquisa, guias e } \\
\text { publicações }\end{array}$ \\
\hline 4) Acesso & 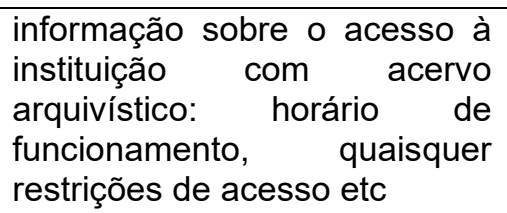 & $\begin{array}{l}17 \text { Horário de funcionamento } \\
18 \text { Condições e requisitos para acesso } \\
\text { e uso } \\
19 \text { Acessibilidade }\end{array}$ \\
\hline 5) Serviços & $\begin{array}{l}\text { informação relevante sobre os } \\
\text { serviços técnicos oferecidos } \\
\text { pela instituição com acervo } \\
\text { arquivístico }\end{array}$ & $\begin{array}{l}20 \text { Serviços de pesquisa } \\
21 \text { Serviços de reprodução } \\
22 \text { Áreas públicas }\end{array}$ \\
\hline 6) Controle & 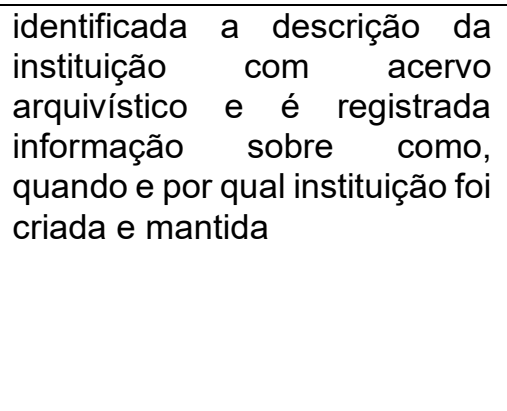 & $\begin{array}{l}23 \text { Identificador da descrição } \\
24 \text { Identificador da instituição } \\
25 \text { Regras e/ou convenções utilizadas } \\
26 \text { Status } \\
27 \text { Nível de detalhamento } \\
28 \text { Datas de criação, revisão ou } \\
\text { obsolescência } \\
29 \text { Idioma(s) e sistema(s) de escrita } \\
30 \text { Fontes } \\
31 \text { Notas de manutenção }\end{array}$ \\
\hline
\end{tabular}

Fonte: Adaptado de CONARQ, 2009.

Assim como a ISAAR (CPF), a ISDIAH orienta acerca do relacionamento de informação sobre instituições com acervo arquivístico a descrições multinível segundo a ISAD $(G)$ e a descrições conformes à ISAAR (CPF) de entidades coletivas, famílias e pessoas como produtoras de material arquivístico. 
Já a ISDF, que também foi elaborada por um grupo do Comitê de Boas Práticas e Normas (ClA/CBPN), foi criada a partir do reconhecimento da importância das funções no contexto de produção dos documentos levou o grupo a propor a elaboração de uma norma para a descrição de funções em sistemas arquivísticos de informação.

A experiência bem-sucedida de modelos de descrição e análise de funções em arquivos e em gestão de documentos em países como Austrália, Canadá, Suíça, Reino Unido e Estados Unidos da América, assim como o trabalho internacional realizado pela International Organization for Standardization (ISO), como a ISO 15489 - International Standard on Records Management (2001) e a ISO 23081 - International Standard on Records Management Processes - Metadata for Records (2006-2007), fomentaram as discussões e reflexões servindo como base para a ISDF. (CONARQ, 2008)

Dessa forma, a ISDF é responsável por dar diretivas para a preparação de descrições de funções de entidades coletivas associadas à produção e manutenção de arquivos, entendendo a compreensão das funções institucionais elementos importantes para sistematizar as atividades técnicas do arquivo. Para tal, sua estrutura é composta por 23 elementos de descrição, agrupados em 4 áreas, conforme apresentado no Quadro 8.

Quadro 8 - Estrutura dos Elementos de descrição da ISDF.

\begin{tabular}{|c|c|c|}
\hline ÁREA & FUNÇÃO & ELEMENTOS DE DESCRIÇÃO \\
\hline 1) Identificação & $\begin{array}{l}\text { informação visa identificar } \\
\text { especificamente a função e } \\
\text { define um ponto de acesso } \\
\text { normalizado }\end{array}$ & $\begin{array}{l}1 \text { Tipo } \\
2 \text { Forma(s) autorizada(s) do nome } \\
3 \text { Forma(s) paralela(s) do nome } \\
4 \text { Outra(s) forma(s) do nome } \\
5 \text { Classificação }\end{array}$ \\
\hline 2) Descrição & $\begin{array}{lcr}\text { informação } & \text { sobre } & \text { a } \\
\text { natureza } & \text { e contexto } & \text { da } \\
\text { função } & & \end{array}$ & $\begin{array}{l}6 \text { Datas } \\
7 \text { Descrição } \\
8 \text { História } \\
9 \text { Legislação }\end{array}$ \\
\hline 3) Relacionamentos & $\begin{array}{l}\text { relações com outras } \\
\text { funções são registradas e } \\
\text { descritas }\end{array}$ & $\begin{array}{l}10 \text { Forma(s) autorizada(s) do } \\
\text { nome/ldentificador da função } \\
\text { relacionada } \\
11 \text { Tipo } \\
12 \text { Categoria do relacionamento } \\
13 \text { Descrição do relacionamento } \\
14 \text { Datas do relacionamento }\end{array}$ \\
\hline
\end{tabular}




\begin{tabular}{|l|l|l|}
\hline 4$)$ Controle & descrição de uma função é & 15 Identificador da descrição da função \\
& especificamente & 16 Identificadores da instituição \\
& identificada, e registrada a & 17 Regras e/ou convenções utilizadas \\
& informação sobre como, & 18 Status \\
quando e por qual & 19 Nível de detalhamento \\
instituição arquivística a & 20 Datas de criação, revisão ou \\
descrição foi criada e e & obsolescência \\
mantida & 21 Idioma(s) e forma(s) de escrita \\
& 22 Fontes \\
& 23 Notas de manutenção \\
\hline
\end{tabular}

Fonte: Adaptado de ISDF (2008a).

Assim como a ISAAR (CPF) e a ISDIAH, a ISDF orienta acerca do relacionamento de informação sobre instituições com acervo arquivístico a descrições multinível, mostrando como essas associações podem ser criadas.

Analisando as estruturas dos instrumentos normativos de descrição arquivística propostos pelo Conselho Internacional de Arquivos, percebe-se que cada uma das normas tem por objetivo a representação da informação por meio da descrição de documentos arquivísticos, de autoridades, de instituições arquivísticas ou com acervo arquivístico e das funções e atividades que envolvem o fluxo informacional em uma instituição.

c) Reflexões acerca de formulação de metodologias e modelo de elementos informativos para estrutura de diagnóstico arquivístico.

O diagnóstico é responsável por evidenciar informações acerca do contexto de criação dos documentos, com elementos referentes à estrutura organizacional e legislativa de onde está inserido, assim como informações de conteúdo, com elementos que expõe os assuntos e estrutura arquivística do acervo.

Ao analisar a estrutura de cada um dos instrumentos normativos de descrição arquivística (ISAD (G), ISAAR (CPF) e a ISDIAH, a ISDF) é possível perceber que a estrutura de cada uma delas retrata exatamente as informações de contexto e conteúdo, que são necessárias para a concepção e desenvolvimento de diagnósticos arquivísticos. Tratando de contexto institucional, a partir dos elementos descritivos propostos pela ISDIAH e de contexto de produção dos documentos, a partir dos elementos descritivos propostos pela ISDF. Quanto ao conteúdo dos documentos, pode-se 
compreender a ISAD (G) com informações elementares para essa descrição. Quanto aos elementos descritivos propostos pela ISAAR (CPF), são transversais às informações de contexto e conteúdo, que para melhor representar-se é possível fazer o uso da descrição de instituições, pessoas e entidades coletivas.

Percebe-se, a partir da análise de literatura, que as informações que compõe a coleta de dados para o desenvolvimento do diagnóstico arquivístico, correspondem aos elementos descritivos propostos pelos instrumentos normativos de descrição arquivística propostos pelo CIA. As metodologias identificadas na literatura para a realização do diagnóstico arquivístico, preconizam o uso de técnicas advindas de outras áreas de conhecimento, porém Santos (2006) preconiza o uso de alguns campos da ISAD (G) para realizar essa coleta de dados.

Porém, principal proposição desse estudo é vislumbrar o uso dos elementos descritivos e informacionais de instrumentos normativos de descrição arquivística, de modo integral, para que a coleta de dados acerca de informações utilizadas para compor o diagnóstico arquivístico, na intenção de retratar a realidade administrativa e arquivística da instituição para que seja possível o planejamento e execução de políticas e intervenções arquivísticas no acervo.

Essa proposta entra em consonância com Almeida e Vitoriano (2018)

Evidencia-se a necessidade de ampliar o conceito de diagnóstico de arquivo e padronizá-lo, porque se entende que esse momento é fundamental para o arquivista conhecer a organização e, a partir das informações coletadas, propor medidas e possíveis soluções para os problemas identificados. (ALMEIDA; VITORIANO, 2018, p. 69)

Dessa forma, lança-se um diferente olhar para a utilização de normativas já consagradas na área arquivística, como as normas de descrição, para serem utilizadas em uma atividade diferente da proposta como objetivo inicial. Assim, as informações descritivas sobre a instituição e seu acervo poderão ser mais concisas e coerentes para tornar mais consistente o mapeamento do cenário que será diagnosticado.

Obviamente, o arquivista poderá flexibilizar o uso e o desuso de elementos descritivos, de acordo com as especificidades que encontrar no ambiente que for aplicar a metodologia descritiva para a coleta de informações 
no desenvolvimento de diagnóstico arquivístico.

\section{CONSIDERAÇÕES FINAIS}

O diagnóstico arquivístico precisa ser percebido como um agente que destaca soluções que priorizam mudanças no tratamento dos documentos, servindo de maneira basilar no planejamento de políticas, programas e planos de gestão de documentos. Não há como implantar atividades arquivísticas em uma organização sem antes traçar um mapeamento sobre a atual situação da instituição.

Destaca-se a necessidade de que as pesquisas e relatos de experiência acerca de diagnóstico arquivístico, façam o uso da terminologia específica da área e tragam para discussão e explanação de seu estudo um referencial teórico que corresponda às proposições do trabalho, fomentando cada vez mais as discussões acerca do diagnóstico arquivístico.

A partir da proposição do uso de instrumentos normativos de descrição arquivística para o desenvolvimento de diagnósticos, é possível conceber extensão do conceito de diagnóstico arquivístico, para que seja compreendido como uma descrição de informações acerca de contexto e conteúdo de uma instituição e seu acervo.

Para isso, a proposta deste estudo nos encaminha para o uso dos elementos descritivos propostos pelas normas internacionais de descrição arquivística (ISAD (G), ISAAR (CPF) e a ISDIAH, a ISDF), como uma possível metodologia para a execução de diagnósticos arquivísticos.

A metodologia proposta, pode ser utilizada em todo e qualquer cenário arquivístico para endossar as formas de compreender as estruturas organizacionais e arquivísticas da instituição. $O$ arquivista poderá selecionar os campos descritivos que considerar conveniente, ou até mesmo partir de todos os elementos informativos propostos para que não influencie em nenhum aspecto do diagnóstico.

Ressalta-se a importância da arquivística olhar para si mesma, para sua teoria e para sua prática, na busca de esclarecimentos para seus fazeres. 
Integrando-se e revisitando respostas de antigas problemáticas e as adaptando e aplicando à outras demandas.

\section{REFERÊNCIAS}

ALMEIDA, M. F. I.; VITORIANO, M. C. C. P. Diagnóstico de arquivos e mapeamento da informação: interlocução da gestão documental com a gestão da informação. Em Questão, Porto Alegre, v. 24, n. 3, p. 68-95, st./dez., 2018. Disponível em: http://www.brapci.inf.br/index.php/res/download/46744. Acesso em: 09 out. 2018.

ARQUIVO NACIONAL. Dicionário brasileiro de terminologia arquivística. Rio de Janeiro: Arquivo Nacional, 2005. 232 p.

BRASIL. Lei n. 8159 de 8 de janeiro de 1991. Dispõe sobre a política nacional de arquivos públicos e privados e dá outras providências. Brasília, DF: Presidência da República, 1991. Disponível em: http://www.planalto.gov.br/ccivil_03/LEIS/L8159.htm. Acesso em: 03 dez. 2018.

CALDERON, W. R.; CORNELSEN, J. M.; PAVEZI, N.; LOPES, M. A. O processo de gestão documental e da informação arquivística no ambiente universitário. Ci. Inf., Brasília, v. 33, n. 3, p. 97-104, set./dez. 2004.

CAMPOS, A. M. V. C.; OLIVEIRA, E. B. de; RESENDE, M. E. de; DUBOC, S. B.; CAUVILLE, V. G. Metodologia para diagnóstico de arquivos correntes em organismos da Administração Pública Federal. Arq.\& Adm., Rio de Janeiro, v.10/14, n.2, p.14-23, 1986. Disponível em:

http://www.brapci.inf.br/index.php/article/view/0000003804/8b0fab76af95de2b3 957c7c4c0b39f98/. Acesso em: 19 dez. 2019.

CONSELHO INTERNACIONAL DE ARQUIVOS. ISAAR(CPF): norma internacional de registro de autoridade arquivística para entidades coletivas, pessoas e famílias/tradução de Vitor Manoel Marques da Fonseca. 2. ed., Rio de Janeiro: Arquivo Nacional, 2004. Disponível em:

http://conarq.arquivonacional.gov.br/images/publicacoes_textos/isaar_cpf.pdf Acesso em: 29 dez. 2019.

CONSELHO INTERNACIONAL DE ARQUIVOS. ISAD(G): Norma Internacional de Descrição Arquivística. 2.ed. Rio de Janeiro: Arquivo Nacional, 2000.

(Publicações técnicas, n. 49). Disponível em: http://conarq.arquivonacional.gov.br/images/publicacoes_textos/isad_g_2001.p df. Acesso em: 03 dez. 2018.

CONSELHO INTERNACIONAL DE ARQUIVOS. ISDF: Norma internacional para descrição de funções. Rio de Janeiro: Arquivo Nacional, 2008.

(Publicações Técnicas; n. 52). Disponível em: 
http://conarq.arquivonacional.gov.br/images/publicacoes_textos/ISDF.pdf Acesso em: 29 dez. 2019.

CONSELHO INTERNACIONAL DE ARQUIVOS. ISDIAH: Norma internacional para descrição de instituições com acervo arquivístico/Conselho Internacional de Arquivos; tradução de Vitor Manoel Marques da Fonseca. - Rio de Janeiro: Arquivo Nacional, 2009. Disponível em:

http://conarq.arquivonacional.gov.br/images/publicacoes_textos/isdiah.pdf Acesso em: 29 dez. 2019.

CORNELSEN, J. M.; NELLI, V. J. Gestão integrada da informação arquivística: o diagnóstico de arquivos. Arquivística.net, Rio de Janeiro, v. 2, n. 2, p. 70-84, ago./dez., 2006. Disponível em:

http://www.brapci.inf.br/index.php/article/view/0000004445/d91fbe7bdd69bc96c 5116978dba8e43b/. Acesso em: 01 dez. 2018.

CUNHA, M. B. da; CAVALCANTI, C. R. de O. Dicionário de biblioteconomia e arquivologia. Brasília: Briquet de Lemos, 2008, 451p.

DURANTI, L. Origin and development of the concept of archival description. Archivaria: the jornal of the Association of Canadian Archivists. Ottawa, n. 35, p.47-54, 1993.

EVANS, F. B.; KETELAAR, E. Guía para la encuesta sobre los sistemas y servicios de la gestión de documentos y la administración de archivos: um estúdio del RAMP. Programa General de Información y UNISIST. Paris: UNESCO, 1983. 37p.

FEITOZA, R. A. B.; ALMEIDA, S. S.; LIMA, E. S. Diagnóstico arquivístico como instrumento à proposta de uma política de gestão de documentos: um relato de experiência no SEBRAE/PB. Archeion Online, João Pessoa, v. 5, p. 66-83, 2017. Disponível em: http://www.brapci.inf.br/index.php/res/v/14828 . Acesso em: 09 out. 2018.

FERREIRA, L.C.; MELO, D.G. Diagnóstico de arquivo: instrumento de ação efetiva na gestão documental. In: FÓRUM INTERNACIONAL DE ARQUIVOLOGIA, 1., 2008. João Pessoa: UEPB, 2008.CD-ROM.

FONSECA, M. O. K. Informação, arquivos e instituições arquivísticas. Arquivo \& Administração, Rio de Janeiro, v. 1, n. 1, p. 33-44, jan./jun., 1998.

Disponivel em:

http://www.brapci.inf.br/index.php/article/view/0000003793/1ceb8c721cc7b4586 71f3223b1a06448/. Acesso em: 01 dez. 2018.

FOX, M. Por que precisamos de normas. Acervo: revista do Arquivo Nacional. Rio de Janeiro, v. 20, n.1-2, p. 23-30, jan./dez. 2007. Disponível em: http://revistaacervo.an.gov.br/seer/index.php/info/article/view/127. Acesso em: 03 dez. 2018.00 
HEREDIA HERRERA, A. Archivistica general: Teoria y practica. 5 ed. Sevilla: Diputación de Sevilla, 1991. 478 p.

INDOLFO, A. C. Gestão de documentos: uma renovação epistemológica no universo da arquivologia. Arquivística.net, Rio de Janeiro, v. 3, n. 2, p. 28-60, jul./dez., 2007.

LINARES, R.; MENA, M. Introducción a las Ciencias de la Información. La Habana: Universidad de La Habana, 2014.

LLANES PADRÓN, D. La descripción archivística em los tempos pos modernos: conceptos, principios y normas. São Paulo: Cultura Acadêmica, 2016. $155 p$.

LOPES, L. C. A gestão da informação: as organizações, os arquivos e a informática aplicada. Rio de Janeiro: Arquivo Público do Estado do Rio de Janeiro, 1997, 143p.

LOPES, L. C. A nova arquivística na modernização administrativa. 2 ed., Brasília: Projecto Editorial, 2009. 417p.

MEDEIROS, N. L. de; AMARAL, C. M. G. do. A representação do ciclo vital dos documentos: uma discussão sob a ótica da gestão de documentos. Em Questão, Porto Alegre, v. 16, n. 2, jul./dez., 2010, p. 297-310. Disponível em: https://seer.ufrgs.br/EmQuestao/article/view/15108/10436. Acesso em: $01 \mathrm{dez}$. 2018.

MONEDA CORROCHANO, M. de la. El archivo de empresa: un concepto integrado. In: RUIZ RODRIGUEZ, A. A. (Ed.). Manual de archivística. Madrid: Sintesis, 1995. p. 235-262.

OLIVEIRA, T. M. M.; BEDIN, S. P. M. Diagnóstico de arquivo como instrumento de avaliação na gestão documental. Ágora, Florianópolis, v. 28, n. 56, p. 115135, jan./jun., 2018. Disponível em:

http://www.brapci.inf.br/index.php/res/download/48199. Acesso em: 09 out. 2018.

PAZIN, M. Arquivos de empresas: tipologia documental. São Paulo:

Associação de Arquivistas de São Paulo, 2005.

PEREIRA, A. C. S. Aprimorando o sistema de controle interno da Câmara Municipal de Araruama: diagnóstico da situação arquivística do poder legislativo municipal. 2016. 90 f. Dissertação (Mestrado Profissional em Bens Culturais e Projetos Sociais). Fundação Getúlio Vargas, Rio de Janeiro, 2016. Disponível em:

http://bibliotecadigital.fgv.br/dspace/bitstream/handle/10438/16419/Disserta\%C 3\%A7\%C3\%A3o.pdf?sequence=1\&isAllowed=y. Acesso em: 09 out. 2018. 
ROUSSEAU, J.; COUTURE, C. Os fundamentos da disciplina arquivística. Lisboa, Portugal: Publicações Dom Quixote, 1998. 356p.

SANTOS, C. J. O. Diagnóstico dos arquivos das primeiras dioceses católicas brasileiras (1551-1854). In: ENCONTRO NACIONAL DE PESQUISA EM CIÊNCIA DA INFORMAÇÃO, 7., 2006, Marília. Anais [...]. Marília: UNESP, 2006. Disponível em:

http://repositorios.questoesemrede.uff.br/repositorios/handle/123456789/1283 Acesso em: 09 out. 2018.

SILVA, W. A.; MARINHO, S.; SANTOS, P. K. dos. Uma abordagem sistêmica aplicada à arquivística. Arquivística.net, Rio de Janeiro, v. 3, n. 1, p. 54-71, 2007. Disponível em: http://www.brapci.inf.br/index.php/article/download/10724. Acesso em: 09 out. 2018.

SOUZA, V. F. de. Diagnóstico e proposta de aperfeiçoamento para o centro de documentação do laboratório de integração e testes-LIT. 2013. 140 f. Dissertação (Mestrado em Gestão e Desenvolvimento Regional). Universidade de Taubaté, Taubaté, SP, 2013. Disponível em: http://www.bdtd.unitau.br/tedesimplificado/tde_busca/arquivo.php?codArquivo= 705. Acesso em: 09 out. 2018.

VARGAS, L. R. Seção de arquivo permanente do Arquivo Central da Universidade Federal do Rio Grande do Sul: diagnóstico sobre a preservação, a descrição e a difusão dos fundos UPA e URGS. 2017. 213 f. Dissertação (Mestrado em Memória Social e Bens Culturais). Universidade La Salle. Rio de Janeiro. Disponível em: https://lume.ufrgs.br/bitstream/handle/10183/171733/001056897.pdf?sequence $=1$ \&isAllowed=y. Acesso em: 09 out. 2018.

\title{
ARCHIVAL DIAGNOSIS: A METHODOLOGICAL PROPOSITION FROM NORMATIVE INSTRUMENTS OF ARCHIVAL DESCRIPTION
}

\begin{abstract}
Introduction: Discusses the importance and necessity of performing the archival diagnosis in the forefront of any archival intervention in the document management process. Objectives: To approach concepts and methodologies that the literature of the area has used in the archival diagnosis, structure and objectives of the normative instruments of archival description ISAD (G), ISAAR (CPF), ISDIAH and ISDF. Methodology: Bibliographic research that aligns the information proposed by the literature for the development of archival diagnosis with the structure of descriptive elements of the normative instruments of archival description, seeking to identify the concepts and methodologies used in the development of archival diagnosis. Results: Consider the descriptive elements that compose the normative instruments of archival description enough to list the information necessary for the development of the archival diagnosis. It proposes the descriptive methodology for the development of archival
\end{abstract}


diagnosis using the normative instruments of archival description: ISAD (G), ISAAR (CPF), ISDIAH and ISDF. Conclusions: It indicates the importance of determining the information elements from already standardized instruments that can generate archival diagnoses able to correspond to archival solutions according to the actual institutional needs.

Descriptors: Archival diagnosis. Archival description. Normative instruments of archival description. Archival description standards.

\title{
DIAGNÓSTICO ARQUIVISTICO: UNA PROPOSICIÓN METODOLÓGICA A PARTIR DE INSTRUMENTOS NORMATIVOS DE DESCRIPCIÓN ARQUIVIISTICA
}

\begin{abstract}
RESUMEN
Introducción: Analiza la importancia y la necesidad de realizar el diagnóstico archivístico em lo que antecede cualquier intervención archivística em el proceso de gestión de documentos. Objetivo: Discute conceptos y metodologías que la literatura del área ha utilizado para realizar el diagnóstico archivístico, la estructura y los objetivos de los instrumentos normativos de la descripción archivística ISAD (G), ISAAR (CPF), ISDIAH e ISDF.EI objetivo de este trabajo es analizar la relación entre la calidad de la información y la calidad de la información. Metodología: Investigación bibliográfica que alínea las informaciones propuestas por la literatura para el desarrollo de diagnóstico archivístico com la estructura de elementos descriptivos de los instrumentos normativos de descripción archivística, buscando identificar los conceptos y metodologías utilizadas en el desarrollo de diagnóstico archivístico. Resultados: Considera los elementos descriptivos que componen los instrumentos normativos de descripción archivística suficientes para enumerar informaciones necesarias para el desarrollo del diagnóstico archivístico. Propone la metodologia descriptiva para el desarrollo de diagnóstico archivístico utilizando los instrumentos normativos de descripción archivística: ISAD (G), ISAAR (CPF), ISDIAH e ISDF. Conclusiones: Indica la importancia de determinar los elementos informativos a partir de instrumentos ya estandarizados que puedan generar diagnósticos archivísticos capaces de corresponder a las soluciones archivísticas de acuerdo com las reales necessidades institucionales.
\end{abstract}

Descriptores: Diagnóstico de archivo. Descripción archivística. Instrumentos normativos de descripción archivística. Estándares de descripción de archivo. 